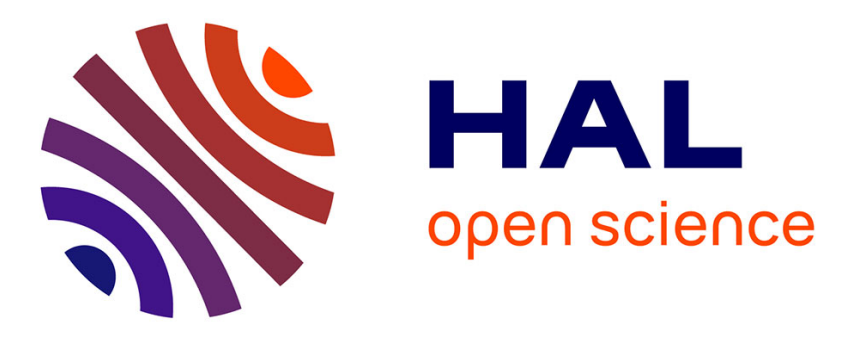

\title{
The value of schedule update frequency on distributed energy storage performance in renewable energy integration
}

\author{
Andrea Michiorri, Arthur Bossavy, Georges Kariniotakis, Robin Girard
}

\section{To cite this version:}

Andrea Michiorri, Arthur Bossavy, Georges Kariniotakis, Robin Girard. The value of schedule update frequency on distributed energy storage performance in renewable energy integration. The 4th IEEE/PES European Innovative Smart Grid Technologies (ISGT), International Conference and Exibition, Oct 2013, Copenhagen, Denmark. 5 p., 10.1109/ISGTEurope.2013.6695299 . hal-00870566

\section{HAL Id: hal-00870566 \\ https: / hal-mines-paristech.archives-ouvertes.fr/hal-00870566}

Submitted on 7 Oct 2013

HAL is a multi-disciplinary open access archive for the deposit and dissemination of scientific research documents, whether they are published or not. The documents may come from teaching and research institutions in France or abroad, or from public or private research centers.
L'archive ouverte pluridisciplinaire HAL, est destinée au dépôt et à la diffusion de documents scientifiques de niveau recherche, publiés ou non, émanant des établissements d'enseignement et de recherche français ou étrangers, des laboratoires publics ou privés. 


\section{The value of schedule update frequency on distributed energy storage performance in renewable energy integration}

\author{
Andrea Michiorri \\ Georges Kariniotakis \\ MINES ParisTech, Centre PERSEE \\ Sophia Antipolis, France \\ andrea.michiorri@mines-paristech.fr
}

\author{
Arthur Bossavy \\ Robin Girard \\ MINES ParisTech, Centre PERSEE \\ Sophia Antipolis, France
}

\begin{abstract}
This paper describes preliminary findings of research on the use of Distributed Energy Storage devices for Renewable Energy integration. The primary objective is to describe the effect of different storage scheduling strategies, and namely the benefits from intraday intraday scheduling on the storage performance in renewable energy integration. Optimal schedules of Distributed Energy Storage devices are based on forecasts of Renewable Energy production, local consumption and prices, along with other criteria. These forecasts tend to have a higher uncertainty for higher time horizons, resulting in losses due to errors and to the underutilization of the assets. The use of frequent schedules updates can reduce part of these drawbacks and this paper aims at quantifying this reduction. The importance of the quantification of the benefits arising from different rescheduling frequencies lies in its influence on the ICT infrastructure necessary to implement it and its cost.
\end{abstract}

Index Terms - Energy storage, Solar power generation, Forecasting

\section{INTRODUCTION}

The objective of this paper is to describe the effect of different Distributed Energy Storage (DES) schedule update frequencies on their performance in renewable energy integration. DES optimal schedules are based on forecasts of Renewable Energy (RE) production, local consumption and prices, along with other criteria. Forecasts are used as input in an optimisation process aiming at minimizing the DES operating cost function taking into account the financial gain of the storage, the achievement of technical objectives or both. The forecasts tend to have a growing uncertainty for higher time horizons, resulting in losses due to errors and to the underutilization of the assets. High uncertainties can be associated to false alerts and missed alerts, and the necessity to maintain a determined risk appetite will result in a reduced utilization of the storage capacity. The use of frequent schedules updates can reduce part of these drawbacks i) by reducing the forecasts uncertainty, ii) by allowing corrective actions to be taken in case of false or missed alerts and iii) to take into account the possibility of corrections to the schedule in the optimisation phase of each plan. In real world applications a higher rescheduling frequency needs of a different and in general more complex and expensive ICT infrastructure to be implemented. Therefore, the quantification of the benefits is important in a cost benefit analysis. The frequency of updates and the type of intelligence necessary to calculate the optimal schedules, along with the size of the battery are also important in the determination of the centralised or decentralised architecture of the control.

It must be noted though, that this paper does not aim at identifying the optimal operating schedule frequency update, which would depend on particular conditions and on the particular optimisation criteria used, but to illustrate and quantify the effect of schedule update frequencies.

\section{A. State of the art}

The interest in the use of storage for grid applications is growing, because of its potential for facilitating renewable energy integration and thanks to innovations in the field of storage technologies [1]. An advantage of DES over large, transmission connected storage facilities such as traditional pumped hydro is that they can be used both for helping the load-generation balance and for solving network congestion problems, since the location is not dependent on particular site characteristics [2].

Because of the dynamic nature of the problem and the relatively high cost of the storage, the use of DES is usually associated with the definition of a schedule considering prices, load or renewable production forecasts, and the eventual constraint violations on the network. At the microgrid level, this is shown clearly in [3], where a DES is used for reducing the effects of the uncertainty in the production of a local wind farm. The study does not consider power flows constraints within the microgrid but is focused on the comparison of different optimisation criteria and methods. In this work, forecasts of wind power production, loads and prices are used for scheduling the storage and the controllable loads. Another example can be found in [4], where the authors propose short 
term (hour ahead) and very short (five minutes ahead) term rescheduling of the original day ahead plan, in order to reduce the operation cost of the grid reducing the effect of forecast errors. The time constraints of the very short time rescheduling are met with the use of a genetic algorithm based optimisation approach, with the solution validated thanks to a power flow.

A similar problem is faced also in [5] and [6]. In the first paper, a fuzzy logic expert system is used with 24 hours ahead photovoltaic production forecasts and one hour ahead wind production forecasts. Also in this case the use of intraday rescheduling was proven to reduce considerably the microgrid's operational cost. In the second, a deterministic and a stochastic optimisation algorithm are compared, showing a slightly better performance for the stochastic algorithm. Moreover, the work compares different rescheduling frequencies in order to quantify the reduction in operating cost related to the uncertainty reduction. For the system considered, an hourly rescheduling can reduce the average replacement reserve of about the $25 \%$ respect to a six hour rescheduling, but unfortunately no information is given on lower rescheduling frequencies. The authors consider also part of this reduction caused by simplifications in modelling the problem.

The use of intraday rescheduling is attractive considering the presence of forecast errors and the possibility of reducing their impact with the use of more recent forecasts or more recent information from the network. An example of such a network management approach is described in [7], where a multi-timescale scheduling approach is developed and applied to a grid with high wind power penetration. The work shows that the multi-timescale approach can reduce the per-unit generation cost by reducing the dispatch of fast start generation.

\section{B. Structure of the paper}

This paper is structures in the following order: in section II, the models used for the forecasts and the batteries are described, along with the procedure use for schedules calculations. In section III the simulation results are presented, after a description of the data used as inputs and finally in section IV conclusions are drawn.

\section{MODELLING}

\section{A. Forecasts}

In this paper, PV production distribution forecasts are obtained using the Quantile Regression Forest (QRF) algorithm [8]. The QRF algorithm estimates the whole cumulative distribution function of the production, then allowing deriving the desired quantiles all at once. Such estimation is made conditionally to the projected surface global solar irradiation at the level of the solar plant. For the model, solar irradiation solar irradiation numerical weather predictions from the European Centre for Medium-Range Weather Forecasts are used, along with measures of effective production from the observed PV plant [9] are used as inputs.

The numerical weather predictions used are available with a three hour resolution and they have been interpolated in order to obtain the half hour resolution requested for this work. The measurements of PV production are available with a resolution of fifteen minutes, and for the same reason, they have been averaged in order to obtain the necessary half hour resolution.

\section{B. Battery schedule optimisation}

The objective of the battery schedule optimisation algorithm is to minimise the cost associated to the exploitation of the battery. For a complete schedule of the battery PLAN $=\left[\mathrm{P}_{1}, \ldots, \mathrm{P}_{\mathrm{T}}\right]$, with $\mathrm{P}_{\mathrm{i}}$ being the power charged or discharged by the battery at time $\mathrm{i}$, the overall cost can be calculated as the sum of three main components, as proposed in [3] and reported in Equation (1).

$$
C(P L A N)=C_{\text {source }}+C_{\text {loss }}+C_{\text {aging }}
$$

where, $C_{\text {Source }}$ represents the cost of importing/exporting power from/to the main grid, $C_{\text {loss }}$ represents the cost associated to the losses in the inverter and the efficiency in the charge/discharge of the battery and $C_{l o l}$ represents the cost of the loss of life of the battery.

The sourcing cost $C_{\text {source }}$ depends on the price $\operatorname{Pr}$ of electricity. In this study, the residential day-night tariff applied in the region of Nice is chosen. The cost is calculated both in the charge and discharge phase, where in the second case, it represents a profit for the battery as reported in Equation (2).

$$
C_{\text {source }}=\Sigma_{h}\left(P_{h} \cdot P r_{h}\right)
$$

The cost $C_{\text {loss }}$ associated to the losses in the inverter and in the electrochemical reactions of the battery, is calculated considering an overall charge/discharge efficiency eff $\in[0,1]$, as shown in Equation (3).

$$
C_{\text {loss }}=\sum_{h}\left(\sqrt{e f f} \cdot \operatorname{abs}\left(C_{\text {source }, h}\right)\right)
$$

The $\operatorname{cost} C_{l o l}$ is relative to the ageing of the battery caused by the charge and discharge cycle. The ageing mechanism is particularly complex, strongly dependent on the Depth of Discharge (DOD) during the discharge, and is described in detail in [10]. In this work, the effect of the temperature is not taken into account and it is considered that the ageing speed increases of a value $\mathrm{x} \in[1,2]$, at each doubling of the DOD. It is assumed also that the maximum number $n$ Cycles of full cycles $(\mathrm{DOD}=100 \%)$ that the battery can withstand is known. With these assumptions the cost $C_{\text {aging }}$ can be calculated as shown in Equation (4), where $B_{C}[€]$ is the initial cost of the battery. The sum on negative DOD is done to take into account that the irreversible reactions contributing to the aging of the battery occur in the discharge phase of the cycle.

$$
C_{\text {aging }}=\Sigma_{h}\left(-\min \left(0, D O D_{h}\right)\right) \cdot B_{C} / n \text { Cycles }
$$

In this study, a gradient-descend optimisation algorithm has been used for minimising the cost function reported in (1). The algorithm, as shown in Equation (5) minimises the sum over the whole period $T$ of the cost for the single horizon $\mathrm{h}$ calculated as in Equation (1), subject to the constraints reported in Equation (6) and Equation (7) and returning the optimal battery schedule.

$$
\begin{gathered}
P L A N_{o p t}=\operatorname{argmin}\left(\Sigma_{h}\left(C_{h}(P L A N)\right)\right) \\
P d_{h} \leq P_{h} \leq P c_{h} \\
S O C_{\min } \leq S O C_{h} \leq S O C_{\max }
\end{gathered}
$$




$$
S O C_{h}=\operatorname{SOC}_{0}+\sum_{i=1, h}\left(P_{i} d t / \text { Bcap }\right)
$$

Where: $P_{h}[\mathrm{~kW}]$, is the power exported or absorbed by the battery at horizon $h, S O C_{h}$, is the state of charge of the battery at horizon $h$, calculated as in Equation (8) $P d_{h}, P c_{h}[\mathrm{~kW}]$, are respectively the maximum charge and discharge power of the battery that can change in relation to the situation of the network at horizon $h, S O C_{\min }$, $S O C_{\max }$, are respectively the minimum and maximum allowable state of charge of the battery and Bcap $[\mathrm{kWh}]$ is the capacity of the battery.

\section{Battery PV integration}

Central to the definition of the problem is the relation between the PV plant and the battery. The system considered in this paper is composed by two different entities, where the battery offers a service to the PV producer on a day ahead contract. In this study it is assumed that the export capacity of the PV producer is limited to a threshold thr equivalent to the $50 \%$ of the peak rating of the PV plant and the exceeding power is either stored in the battery, or not produced. The mechanism is described below:

1) An initial optimal schedule for the battery $\operatorname{PLAN}(0)$ is calculated by solving the optimisation problem described in (7-9) without considering network constraints in Equation (8).

2) For each quantile $\alpha$ of the probabilistic forecasts an array of flexibility needed $F L E X=\left[F_{1}, \ldots, F_{T}\right]$ is calculated as described in (9). Negative velues represent energy that must be absorbed by the battery, whilst positive values represent the maximum discharge allowed to the battery.

$$
F h(\alpha)=t h r-q t+h \mid t(\alpha)
$$

3) The corresponding battery schedule $\operatorname{PLAN}(\alpha)$ is calculated solving the optimisation problems described in (57), imposing the flexibility $\operatorname{FLEX}(\alpha)$ as the minimum (in absolute value) discharge power of the battery, as reported in (10), where the maximum discharge capacity of the battery $P d$ is also taken into account. If the total amount of energy of the flexibility demanded is greater than the capacity of the battery, a correction factor is calculated and applied to the flexibility request. The cost associated with the plan $C(\alpha)$ is calculated as the difference between the cost of the schedule $\operatorname{PLAN}(\alpha)$ and the schedule PLAN $(0)$, as described in (11)

$$
\begin{gathered}
P d_{h}=\min \left(F_{h}(\alpha), P d\right) \\
C(\alpha)=C(P \operatorname{LAN}(\alpha))-C(P \operatorname{LAN}(0))
\end{gathered}
$$

The expected profit $\mathrm{EP}_{\mathrm{PV}}$ for the $\mathrm{PV}$ associated to the flexibility $\operatorname{FLEX}(\mathrm{h}, \alpha)$ is calculated as described in (12).

$$
\operatorname{EPPV}(\alpha)=-\Sigma_{h}\left(\min \left(0, F_{h}(\alpha)\right) \cdot P r_{h}\right) \quad(1-\alpha)
$$

4) The expected profit for the system $\mathrm{EP}_{\mathrm{SYS}}$ is then calculated as the difference between the expected profit $\mathrm{EP}_{\mathrm{PV}}(\alpha)$ and the disoptimisation cost of the battery $\mathrm{C}(\alpha)$.

5) The steps 2-4 are then repeated for each quantile of the forecasts and finally the quantile $\alpha_{\mathrm{opt}}$ corresponding to the maximum expected profit for the system is identified, along with the optimal schedule $\operatorname{PLAN}\left(\alpha_{\text {opt }}\right)$.
6) The effective profit for the PV $T P_{P V}$ is then calculated as in Equation (12), by considering the effective measured PV production $\mathrm{Y}$ instead of the forecasted production $\mathrm{q}_{\mathrm{t}+\mathrm{h} \mid \mathrm{t}}\left(\alpha_{\mathrm{opt}}\right)$.

A visual representation of the process described is presented in Figure 1.

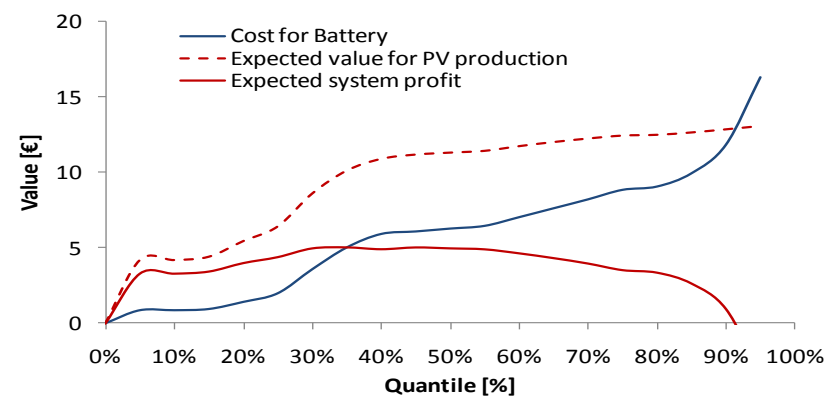

Figure 1. Cost benefit analysis of the flexibility requested at different forecast quantiles

\section{Simulations}

\section{A. Case-study}

This section describes the data used in this work, in particular the data relative to DES characteristics, photovoltaic production and electricity prices.

Regarding the DES, a lithium-ion battery with a storage capacity of $100 \mathrm{kWh}$ has been considered in this work. The maximum discharge power has been fixed at $150 \mathrm{~kW}$ and the maximum charge power at $50 \mathrm{~kW}$. This is to take into account the fact that usually the maximum charge speed of batteries is slower than the maximum speed of discharge, and their ratio, in Li-ion batteries, is about $1 / 3 \mathrm{rd}$. A summary of the parameters used in the battery model is reported in TABLE I.

TABLE I. SUMMARY OF BATTERY PARAMETERS

\begin{tabular}{|l|c|c|}
\hline \multicolumn{1}{|c|}{ Parameter } & Dimension & Value \\
\hline Charge power & $\mathrm{kW}$ & 50 \\
\hline Discharge power & $\mathrm{kW}$ & 150 \\
\hline Storage capacity & $\mathrm{kWh}$ & 100 \\
\hline Charge-discharge losses & $\%$ & 5 \\
\hline Battery life & $\mathrm{n}^{\circ}$ of cycles & 5000 \\
\hline Cost & $€ / \mathrm{kWh}$ & 1000 \\
\hline
\end{tabular}

Regarding photovoltaic production, the data obtained from [10] have been used. They consist of a continuous time series covering the period from March 2010 to December 2011 with a temporal resolution of 30 minutes. The production data do not present irregularities due to particular orientations or shadowing and can be considered as representative of typical PV plants, with a daily bell shaped curve and a production lower in winter than in summer. Regarding the electricity prices used in the DES optimisation algorithm and to evaluate the financial benefits of the intra-day rescheduling, the wholesale electricity prices for the French market have been used. The data are made of a time series covering the period from January 2010 and December 2011 with hourly values. 
The data are described in Figure 2 and Figure 3, where the distribution of the production and of electricity prices is shown on an hourly and seasonal basis respectively and the first, fifth and tenth deciles are highlighted.

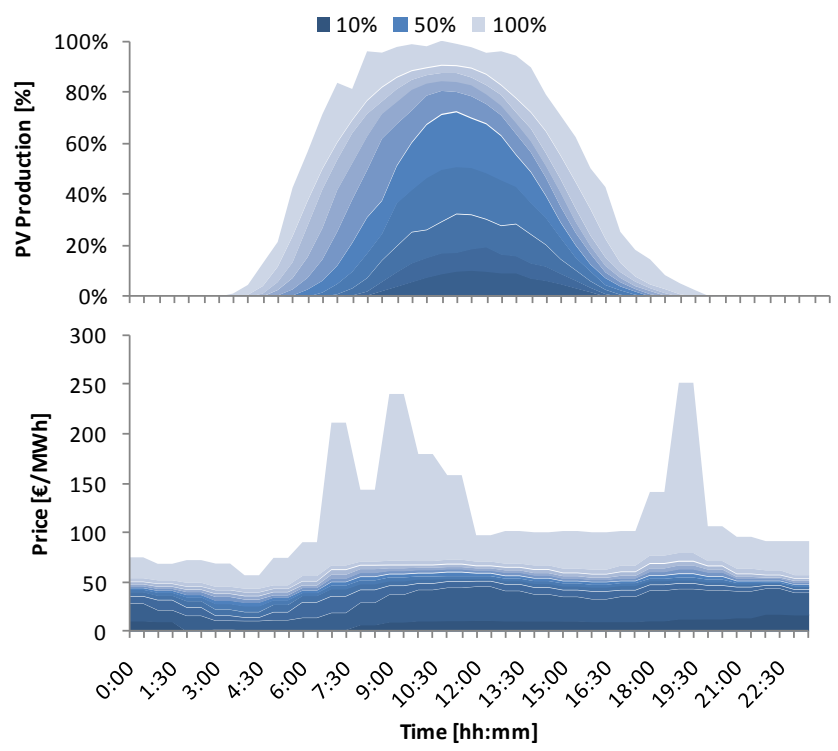

Figure 2. Daily distribution of the dimensionless production of the PV plant for the period $03 / 2010-12 / 2011$ and of the wholesale electricity prices for the period $01 / 2010-12 / 2011$

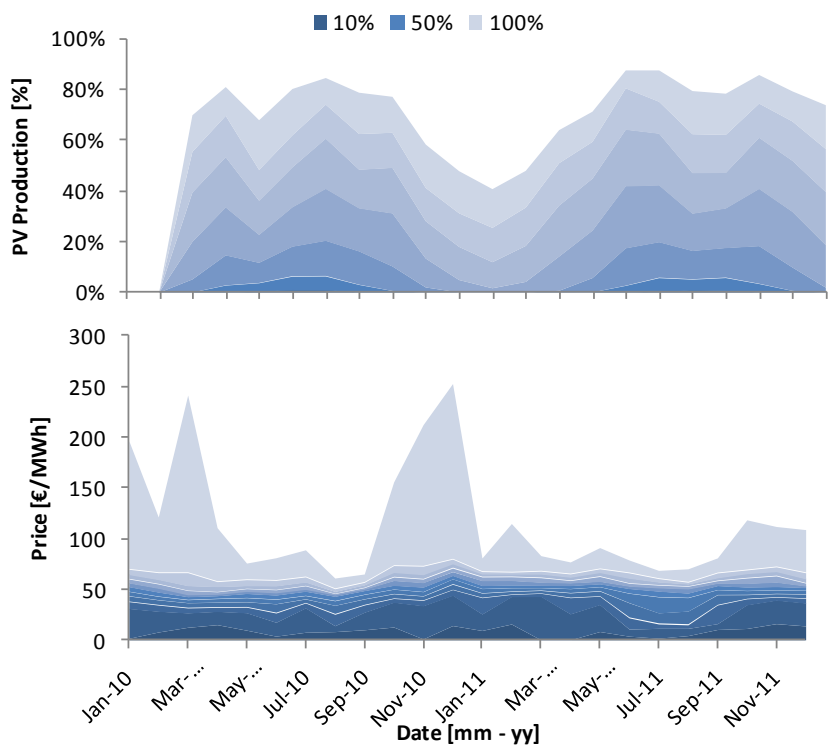

Figure 3. Seasonal distribution of the dimensionless production of the PV plant for the period $03 / 2010-12 / 2011$ and of the wholesale electricity prices for the period $01 / 2010-12 / 2011$

\section{B. Results}

The results of the study are presented in Figure 4, where indicators for the operating profit for the PV-Battery system and for the utilisation level of the battery are reported.

The profit of the system is represented through the ratio between the profit calculated as in Equation (2) and the profit that would be obtained by the PV plant alone without the presence of the export constraints. Figure 4 shows that this ratio is roughly constant in the range of $60 \%$ for update frequencies between 24 and 12 hours, and increases up to $80 \%$ when forecasts and battery schedules are updated with a frequency of one hour. These results are dependent on the prices for the electricity and the capital cost of the battery, but also on the capacity of the battery, both in $\mathrm{kW}$ and in $\mathrm{kWh}$.

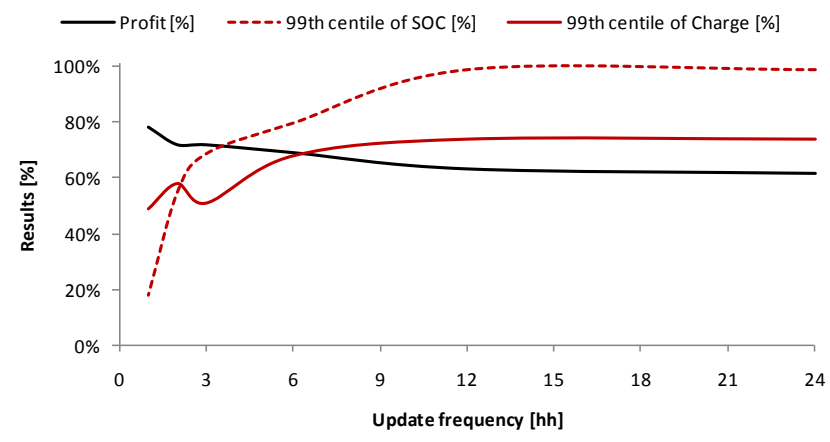

Figure 4. Qualitative representation of the study results: financial value vs schedule update frequency.

In order to show this aspect of the problem, Figure 4 reports also the behaviour of two indicators linked to the utilisation of the energy capacity of the battery and of its charge power. The red dashed line reports the 99 th percentile of the calculated SOC during the simulation period and the solid red line reports the 99th percentile of the simulated charging power of the battery. The 99th percentile is used instead of the maximum value (equivalent to the 100th percentile) because the latter is almost always equal to one, but the 99th percentile gives a better representation of the real utilisation of the battery by filtering extreme values. The two lines show that with a growing update frequency, the utilisation of the battery decreases, especially for the SOC. This can be associated to the reduction of the correlation of forecast errors. A direct consequence of this is that with a higher update frequency a smaller battery can be used with the same performance or that, in presence of a smaller battery, a large update frequency would not be able to solve the PV export problem with a low update frequency.

At this point, it is possible to calculate the quantitative financial benefit of different rescheduling frequencies on the performance of the system. This value can then be used in a cost benefit analysis taking into account the cost and the necessary performance of the necessary ICT infrastructure. It is therefore necessary to compare the increase in profit with the reduction in capital expenditure given by the possibility to use a smaller battery. For this, the net present value of the system's profit, as calculated in Equation (12) for an expected lifetime of about 15 years and a discount factor of $10 \%$ is summed to the savings originated from the possible reduction in the power and energy rating of the battery. The results are then reported in Figure 5 and TABLE II for each $\mathrm{kW}$ of installed PV power.

The results are calculated for four different cases, corresponding to different values of the cost of the battery, representing different batteries technologies or different stages of development of the same technology. The cost of the power 
rating of the battery has not been changed because it is expected to be less variable. The details of the four cases considered are reported below:

$$
\begin{array}{ll}
\text { - } & \text { Case A: } 800 € / \mathrm{kWh}, 200 € / \mathrm{kW} \\
\text { - } & \text { Case B: } 600 € / \mathrm{kWh}, 200 € / \mathrm{kW} \\
\text { - } & \text { Case C: } 400 € / \mathrm{kWh}, 200 € / \mathrm{kW} \\
\text { - } & \text { Case D: } 200 € / \mathrm{kWh}, 200 € / \mathrm{kW}
\end{array}
$$

The results are shown in Figure 5, where the value of the rescheduling frequency is plotted for the four cases. This value can be considered as the headroom available for the cost of ICT, taking into account the initial capital cost and the operating cost made of data transfer, electricity consumption, maintenance, subscription to eventual forecast services, etc... It is possible to see that, at least for the simple case study considered, there is little difference in total performance for a rescheduling frequency larger than 12 hours. It is believed that this may be caused by the saturation of the battery. For smaller update frequencies the value for the system increases considerably, arriving to be comparable with the initial capital cost of the battery. On the other side, it must be considered that the absolute value of the gain per $\mathrm{kW}$ may be modest, representing a barrier for applications in small systems such as domestic batteries.

TABLE II FINANCIAL VALUE OF DIFFERENT SCHEDULE UPDATE FREQUENCIES

\begin{tabular}{|c|c|c|c|c|c|c|c|}
\hline \multicolumn{2}{|c|}{ Update frequency [hh] } & $\mathbf{2 4}$ & $\mathbf{1 2}$ & $\mathbf{6}$ & $\mathbf{3}$ & $\mathbf{2}$ & $\mathbf{1}$ \\
\hline \multirow{3}{*}{$\begin{array}{c}\text { Financial } \\
\text { value } \\
{[\mathbf{E} / \mathbf{k W}]}\end{array}$} & Case A & 260 & 265 & 450 & 581 & 679 & 1011 \\
\cline { 2 - 8 } & Case B & 258 & 263 & 409 & 519 & 588 & 846 \\
\cline { 2 - 8 } & Case C & 256 & 261 & 369 & 456 & 498 & 682 \\
\cline { 2 - 8 } & Case D & 254 & 259 & 328 & 394 & 408 & 517 \\
\hline
\end{tabular}

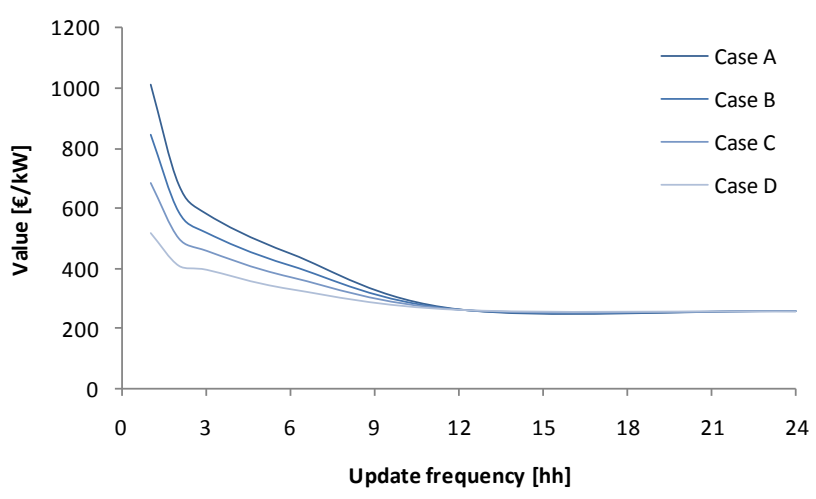

Figure 5: Financial value of different schedule update frequencies

\section{CONCLUSIONS}

The results of a study on the value of Distributed Energy Storage rescheduling frequency on its operating performance have been reported in this paper. It is verified that the performance increases along with the increase of the rescheduling frequency and the improvement between the two extreme rescheduling frequencies of 24 hours and 1 hour) has been quantified in about the $20 \%$. The work highlighted also the importance of the battery size on the results, showing that an increased forecast and rescheduling frequency lead to a reduction in the utilisation of the battery. This reduction has been quantified in about the $80 \%$ and the $20 \%$ for the energy rating and the power rating respectively. It is opinion of the authors that the reduced utilisation of the energy storage is due to the possibility for the battery to reduce the effect of forecast errors autocorrelation. The study shown also how, high rescheduling frequencies can generate a value comparable with the initial capital cost of the battery. On the other side, the little absolute value of this gain may represent a limiting factor in the case of small batteries such as in domestic applications. These two observations show the importance to take into account the rescheduling frequency and the necessary ICT infrastructure for the management of batteries and, in general, for advanced power system applications.

\section{ACNOWLEDGMENT}

The authors wish to thank the personnel of ERDF Méditerranée for their support. This research is realised in the frame of the NiceGrid project, funded in part by ADEME, and the Grid4EU project, funded in part by the European Commission under the 7th FrameWork Programme. The European Centre for Medium-Range Weather Forecasts is acknowledged for the provision of weather forecasts.

\section{REFERENCES}

[1] P. W. Parfomak, "Energy storage for power grids and electric transportation: a technology assessment", Congressional Research Service, 7-5700, R42455, Mar. 2012.

[2] E. Veldman, M. Gibescu, J.G. Slootweg, W. L. Kling, "Technical benefits of distributed storage and load management in distribution grids", Power Tech 2009, 28/06-02/09, Bucharest, $R O$

[3] LM Costa, G Kariniotakis, "A stochastic dynamic programming model for optimal use of local energy resources in a market environment", Power Tech 2007, 01-05/07/07, Lausanne, CH

[4] M. Silva, H. Morais, Z. Vale, "An integrated approach for distributed energy resource short-term scheduling in smart grids considering realistic power system simulation", Energy Conversion and Management, vol. 64, pp. 273-288, Dec. 2012.

[5] A. Chaouachi, R. M. Kamel, R. Andoulsi, K. Nagasaka, "Multiobjective Intelligent Energy Management for a Microgrid", IEEE Trans. Industrial Electronics, vol. 60 (2), pp. 1688-1699, Apr. 2013.

[6] A. Tuohy, P. Meibom, E. Denny, M. O'Malley, "Unit Commitment for Systems With Significant Wind Penetration", IEEE Trans. Power Systems, vol. 24 (2), pp. 592-601, May 2009.

[7] M. He, S. Murugesan, J. Zhang, "A Multi-Timescale Scheduling Approach for Stochastic Reliability in Smart Grids With Wind Generation and Opportunistic Demand", IEEE Trans. Smart Grid, vol. 4 (1), pp. $521-529$, Mar. 2013.

[8] N. Meinhausen, "Quantile Regression Forests", Journal of Machine Learning Research, vol 7, pp 983-999, 2006

[9] A. Michiorri, A. Bossavy, G. Kariniotakis, R. Girard, "Impact of PV forecasts uncertainty in batteries management in microgrids", Power Tech 2013, 17-20 June 2013, Grenoble, FR

[10] Solaire LGM, http://solaire.lgm.ac-grenoble.fr/, Accessed on May 2013

[11] P. Rong, M. Pedram, "An analytical model for predicting the remaining battery capacity of lithium-ion batteries," Very Large Scale Integration (VLSI) Systems, IEEE Transactions on , vol.14, no.5, pp.441-451, May 2006 